\title{
SECAGEM DA BIOMASSA DE AÇAÍ VIA RADIAÇÃO INFRAVERMELHO
}

\author{
R. B. S. LINS ${ }^{1}$, R. L. SERRA ${ }^{1}$, M. M. PRADO ${ }^{1}$ e L. G. MARQUES ${ }^{1}$ \\ ${ }^{1}$ Universidade Federal de Sergipe, Departamento de Engenharia Química \\ E-mail para contato: renatabslins@gmail.com
}

\begin{abstract}
RESUMO - A crescente produção de açaí no país, que de 2000 a 2013 aumentou em quase 100 mil toneladas gera, também, toneladas de resíduos. Subprodutos orgânicos podem ser utilizados em forma de biomassa para geração de energia. A fim de que a energia térmica empregada na conversão não seja utilizada para remoção de umidade do material, aplica-se anteriormente a secagem. Visando contribuir com essa etapa, este estudo tem como objetivo avaliar a melhor condição da secagem infravermelha contínua dos caroços de açaí, cujo diâmetro avaliado equivale ao eixo maior do esferoide oblato na faixa de 11-12mm. Analisou-se, também, o consumo energético. Como esperado, o aumento da temperatura elevou as taxas de secagem, reduziu a duração do processo e reduziu o consumo.
\end{abstract}

\section{INTRODUÇÃO}

O açaí, fruto advindo do açaizeiro (Euterpe oleracea Mart.), palmeira nativa da região amazônica e consumida tradicionalmente na região agradou o paladar brasileiro.

Do açaí, estirpe, caroço, folha e cacho são considerados resíduos (Nagashi ,2007) e todos podem ser utilizados para a produção energética. Porém, o caroço é o mais promissor para o processo devido à melhores características químicas, físicas e térmicas, além da disponibilidade de fornecimento e de ser o principal subproduto na produção da polpa, pois representa $83 \%$ do fruto (SILVA, et. al. 2004).

O caroço de açaí pode ser utilizado para a produção de energia e, segundo Ortiz (1996) apud Oliveira (2014), há quatro formas de isso acontecer: pirólise, gaseificação, combustão e cocombustão. Para isso, faz-se necessária a prévia secagem dos caroços até 11 a $15 \%$ de umidade em base úmida, conforme Barbosa Neto et al. (2014). Diante disso, buscam-se métodos de secagem eficientes e de baixo custo.

Dentre os métodos de secagem, destaca-se a secagem via radiação infravermelho, cujas vantagens são: (a) a radiação aquece o material uniformemente e sem aquecer o meio; (b) mantém altas taxas de secagem com equipamento simples e compacto; (c) alta eficiência na conversão de energia térmica em calor; (d) alta qualidade dos produtos; (e) fácil controle; (f) fácil associação com outros métodos de aquecimento e (g) baixo custo (Barbosa Neto et al, 2014; Mujumdar, 2015).

À vista disso, este trabalho tem como objetivo avaliar o potencial uso da radiação infravermelho para a secagem de caroços de açaí, através da análise dos fenômenos de transferência 

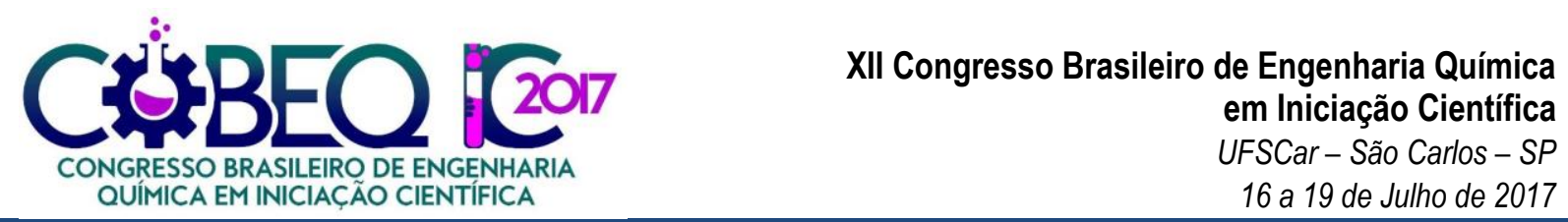

de calor e massa durante a secagem e da avaliação do desempenho do secador IV, em termos de consumo de energia.

\section{MATERIAIS E MÉTODOS}

Os caroços de açaí foram obtidos no estado do Maranhão. A amostra foi limpa e armazenada em freezer a $-5^{\circ} \mathrm{C}$ a fim de manter as condições in natura do material.

Inicialmente foram retiradas as fibras que recobrem os caroços e em seguida, as dimensões foram obtidascom auxílio de um paquímetro digital da marca DIGIMESS com precisão de $10^{-2} \mathrm{~mm}$ para homogeneizar a amostra.

Figura 1 - Comparativo de um esferoide oblato (a) com eixos definidos com o caroço de açaí: (b) vista lateral e (c) vista frontal.

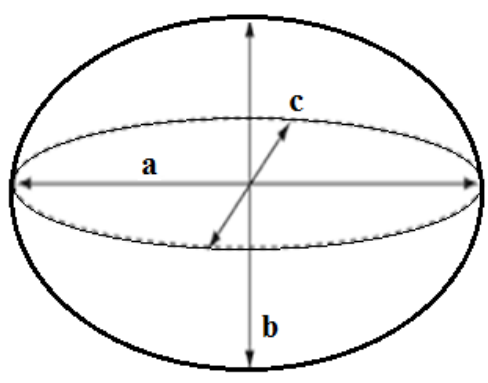

(a)

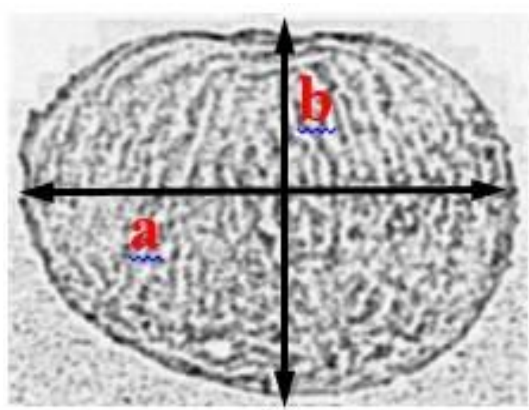

(b)

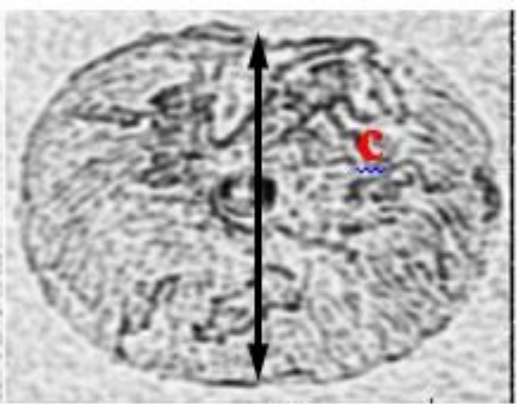

(c)

Fonte: CORREA et al. 2002

Para a determinação da umidade total da amostra foi utilizado o método da estufa a (105 \pm $3)^{\circ} \mathrm{C}$ por um período de 24 horas.

Após retirados da refrigeração, os caroços foram dispostos em monocamada em uma placa circular cuja massa (da placa com os caroços) foi mantida, aproximadamente, constante em $70 \mathrm{~g}$ em todas as corridas.

O estudo da secagem contínua (sem interrupção da emissão de radiação infravermelha pela fonte) foi realizado em um secador infravermelho (Quimis, modelo G333D-2) composto por uma lâmpada incandescente (marca Philips modelo IR 250 RH IR2) com emissão de raios IV de 250W operando entre 230-250V, display digital (Flyever, modelo FE05iN, $1^{\circ} \mathrm{C}$ ) que, por meio de um termopar, controla a temperatura e uma caixa isolada termicamente. $\mathrm{O}$ valor da temperatura era regulado através de um dímer. 

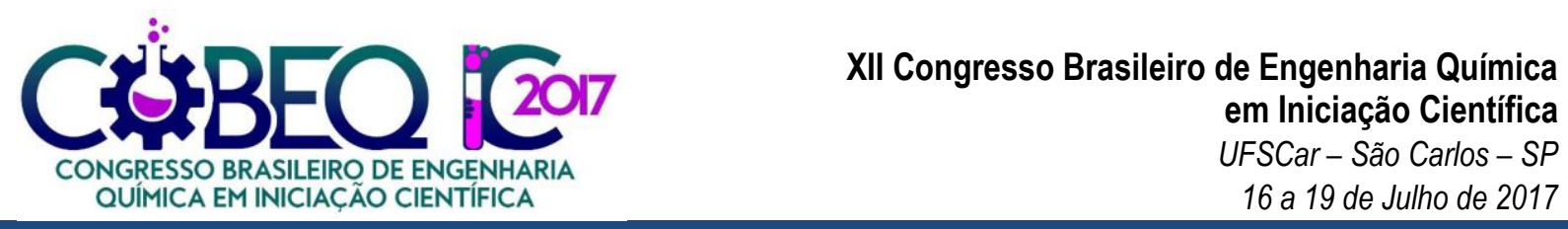

Figura 2: Secador Infravermelho. Fonte: Lima (2012)

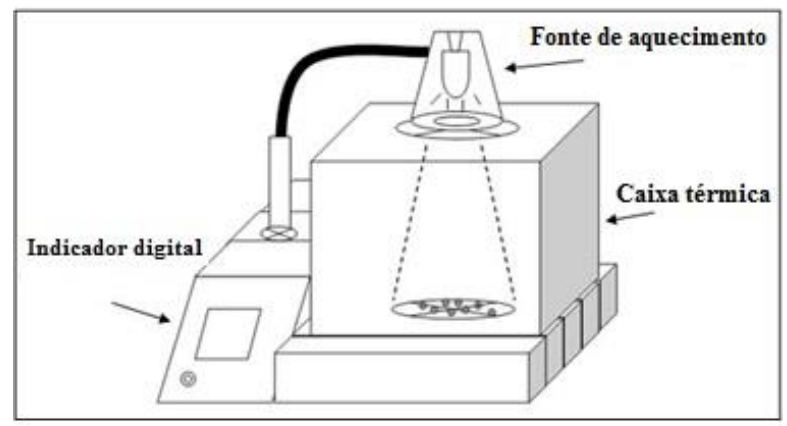

Foram empregadas temperaturas de 100,120 e $140^{\circ} \mathrm{C}$. A partir dos três níveis e um fator, adotou-se um planejamento fatorial com duplicatas nos extremos e triplicata no ponto central, foram feitos 7 experimentos.

Ao ligar o equipamento e ajustada a temperatura, aguardou-se, aproximadamente, 30 minutos, a bandeja com os caroços dispostos em monocamada foi inserida no interior do equipamento a uma distância de $17 \mathrm{~cm}$ da fonte de aquecimento.

Ao longo da secagem foram medidos: a massa da amostra, em uma balança analítica da SHIMADZU modelo AUX 220 com precisão de $1,0 \times 10^{-4} \mathrm{~kg}$; a temperatura superficial do material sólido, com pirômetro digital da IMPAC modelo IP-850; a corrente elétrica medida com um multímetro digitaldo tipo alicate da marca MINIPLA modelo ET-3200 $(0,01 \mathrm{~A})$. A secagem teve fim ao se obter massa constante das amostras (variação de $10^{-5} \mathrm{~g}$ ).

A potência elétrica $(\mathrm{P})$ em Watts foi calculada com base no valor de tensão da rede elétrica (V) em Volts e da corrente elétrica (I) medida em Ampére. A partir desta potência foi possível calcular o consumo energético (E) em $\mathrm{Jkg}^{-1}$ :

$$
\begin{aligned}
& P=V I \\
& E=\frac{P o t \times t_{i n c}}{m_{w}}
\end{aligned}
$$

Sendo $\mathrm{m}_{\mathrm{w}}$ a massa de água removida durante o processo e $\mathrm{t}_{\mathrm{inc}} \mathrm{o}$ tempo de incidência durante a secagem.

\section{RESULTADOS E DISCUSSÃO}

Para a caracterização dos caroços de açaí, o diâmetro considerado equivale ao eixo maior do esferoide, conforme Lima et al (2015) que definiu o eixo maior como a parte representativa do material. Verificou-se que $50 \%$ das partículas estão contidas na faixa de $11-12 \mathrm{~mm}$, conforme mostra a Figura 3. Assim, para garantir que os fenômenos de transporte de energia e massa aconteçam por um mesmo caminho difusional na partícula, adotou-se para os experimentos o diâmetro contido na faixa majoritária em percentual 

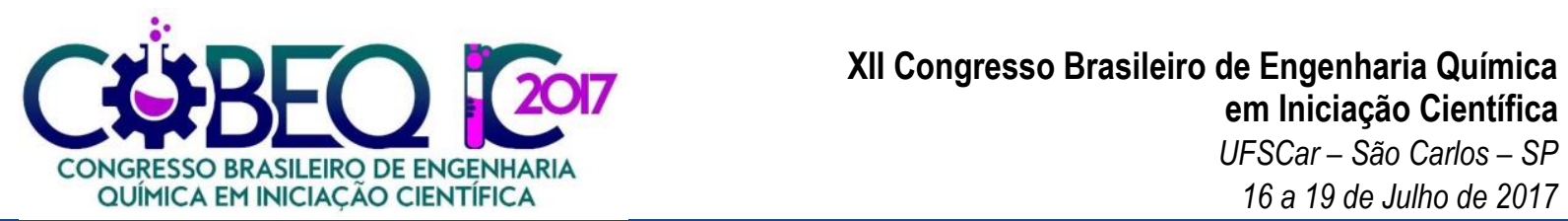

Figura 3: Distribuição da faixa de diâmetro dos caroços de açaí.

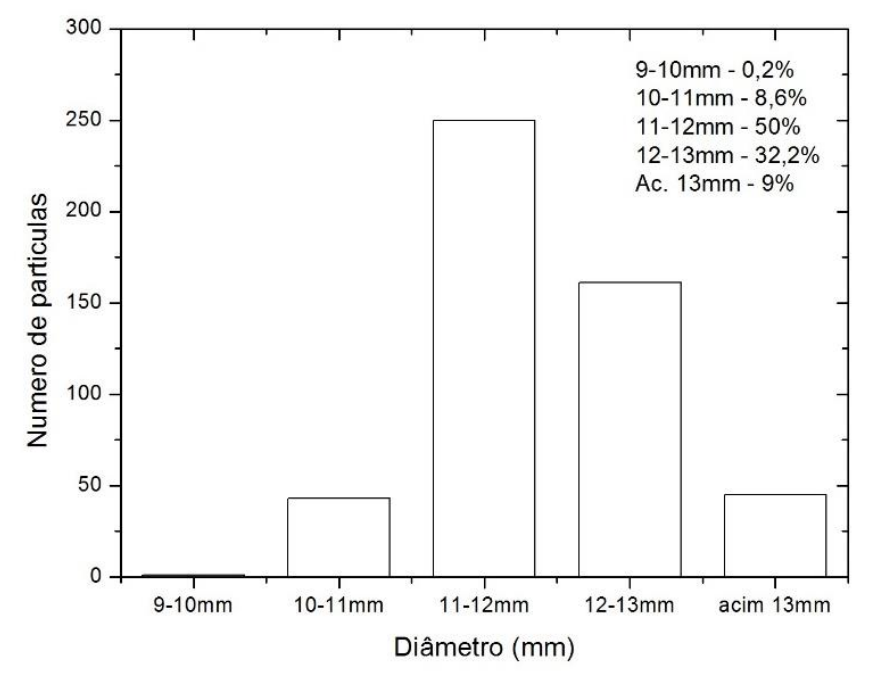

A Figura 4 apresenta o comportamento da temperatura superficial dos caroços $\left(T_{\mathrm{s}}\right)$ com o tempo para a secagem a diferentes temperaturas 100,120 e $140^{\circ}$ da radiação infravermelho. As barras de erro nas curvas de secagem referem-se ao desvio padrão obtido a partir da triplicata no ponto central e duplicatas nos demais pontos.

Figura 4: (a) Temperatura superficial dos caroços de açaí em função do tempo de secagem nas diferentes temperaturas empregadas para o secador IV em processo contínuo. (b) Umidade em base seca dos caroços de açaí em função do tempo de secagem a diferentes temperaturas empregadas para o secador IV contínuo

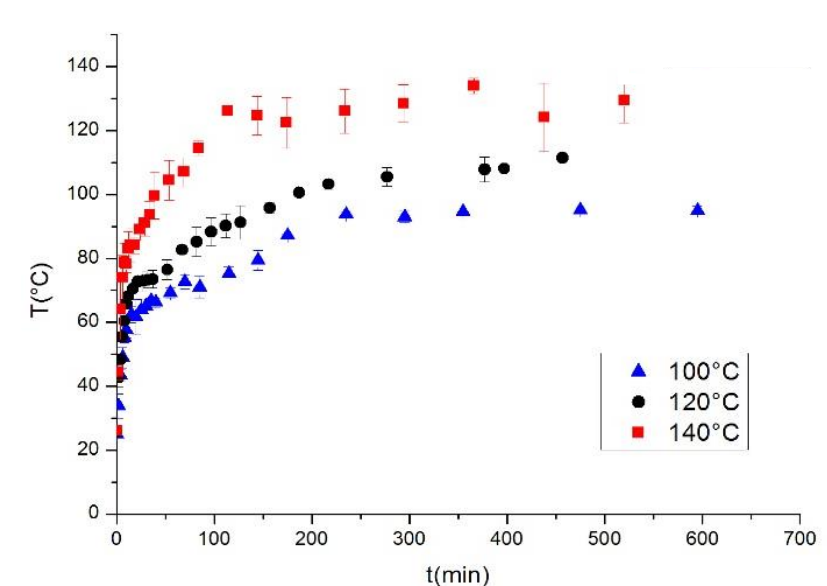

(a)

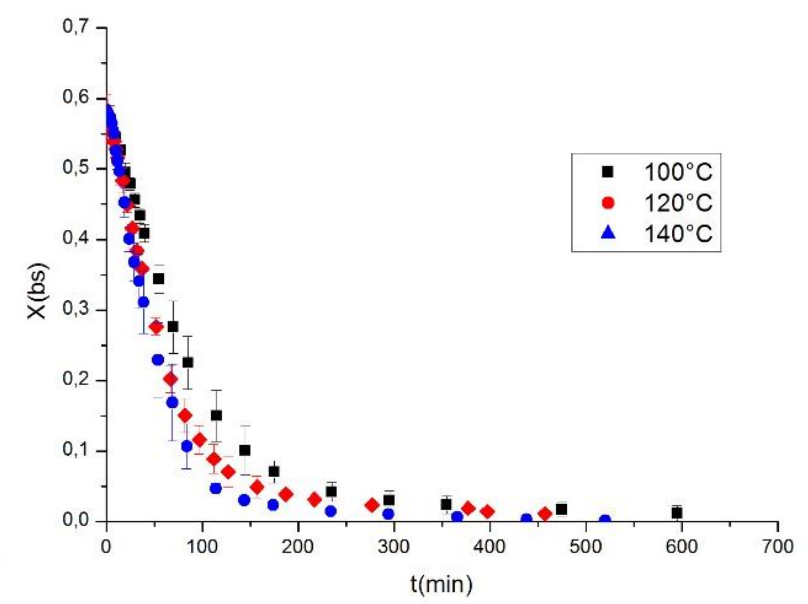

(b) 

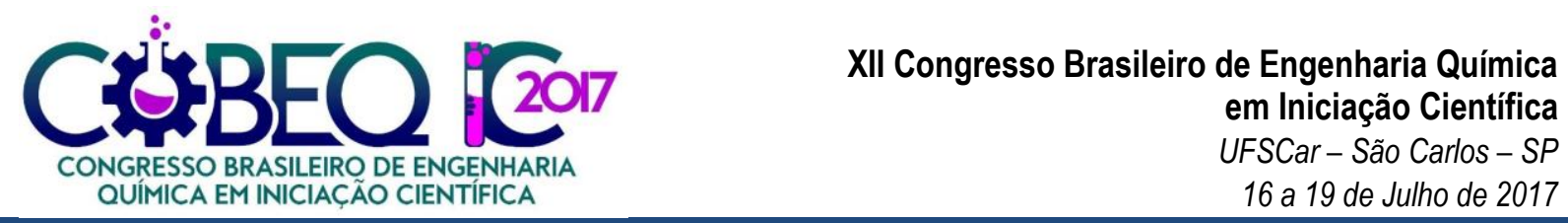

A partir da análise da Figura 4(a) constatou-se que, como esperado, o aumento da temperatura da fonte implica na temperatura superficial significativamente mais alta e, consequentemente, uma redução do tempo de secagem, conforme será apresentado a seguir na cinética e secagem. Além disso, observa-se que há um aquecimento súbito inicial, elevando a temperatura superficial dos caroços rapidamente, que, em seguida, tendem a uma temperatura constante inferior à temperatura da fonte. Isso acontece porque, ainda que a radiação infravermelha aqueça o material sem aquecer o meio, parte da energia que chega às partículas é utilizada para remoção de umidade e outra parte para o aumento da temperatura.

Segundo análise da Figura 4(b), observa-se que com o aumento da temperatura da fonte e, consequentemente, o aumento da temperatura superficial do material, há um aumento na pressão de vapor dos caroços e, por isso, a vaporização é mais eficiente, alcançando menores valores de umidade em um menor período de tempo. A umidade inicial da amostra, que era de $36 \%$ em base úmida atingiu o valor de $2 \%$ a 100,120 e $140^{\circ} \mathrm{C}$ em períodos de 355, 277 e 174 minutos, respectivamente.

Figura 5: Taxa de remoção de umidade em função do tempo para caroços de açaí submetidos à secagem IV contínua nas temperaturas de 100,120 e $140^{\circ} \mathrm{C}$.

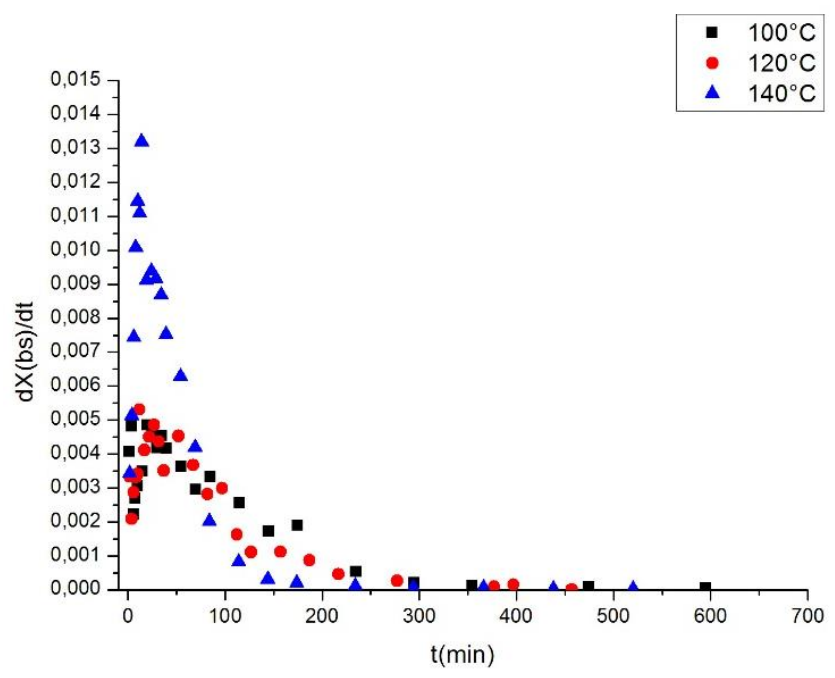

A partir da análise da Figura 5 nota-se que o aquecimento súbito inicial visto na Figura 4 rege um breve período de taxa de secagem crescente, cerca de 15 minutos. Isto é explicado pelo fato da temperatura do sólido ser menor do que a temperatura ambiente, sendo assim, o calor sensível transferido para o sólido é utilizado para evaporar a água do material e elevar a sua temperatura

Com o rápido aparecimento de regiões secas na superfície, não há o período de taxa constante, em que toda energia recebida é utilizada para a vaporização da água superficial. Assim, inicia-se o período de taxa decrescente, com a temperatura superficial aproximadamente constante e próxima da temperatura da fonte, como visto na Figura 4(a). Nota-se que à medida que a umidade diminui, devido à secagem, a velocidade da difusão interna de umidade decresce. 

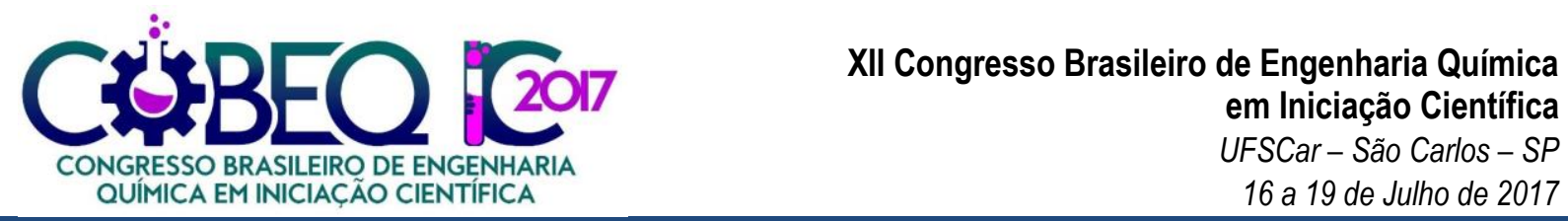

Os valores encontrados para energia específica em todas as temperaturas da fonte de aquecimento IV contínuo foram: $100^{\circ} \mathrm{C}-84,37 \mathrm{MJ} / \mathrm{kg} ; 120^{\circ} \mathrm{C}-61,15 \mathrm{MJ} / \mathrm{kg}$ e $140^{\circ} \mathrm{C}-$ $52,33 \mathrm{MJ} / \mathrm{kg}$.

Verifica-se que, com o aumento da temperatura da fonte, o tempo de secagem diminui, ou seja, o período de incidência da radiação é reduzido. Consequentemente, também é menor o valor do consumo energético.

\section{CONCLUSÕES}

Com base nos experimentos realizados observou-se a inexistência do período de taxa constante. $\mathrm{O}$ aumento da temperatura da fonte resultou em uma temperatura superficial do material mais alta, taxas mais elevadas por um período maior e maior redução da umidade em um menor período de tempo. Ainda, notou-se a redução do consumo energético com o aumento da temperatura.

\section{REFERÊNCIAS BIBLIOGRÁFICAS}

BARBOSA NETO, A. M.; MARQUES, L. G.; PRADO, M. M.; SARTORI, D. J. M. Mass Transfer in InfraredDryingof Gel-CoatedSeeds. Advances in Chemical Engineering and Science, v. 4, n. 1, p. 39-48, 2014.

LIMA, T. M.; OliveIRA, J. C.; SILVA, H. R.; FERNANDES, B. M.; SOARES, T. A. M. Perspectivas para utilização do resíduo de Açaí em Axixá - MA: a solução está nos resíduos. Cadernos de Agroecologia - ISSN 2236-7934 - Vol. 10, № 3 de 2015.

MUJUMDAR, A. S.; editor. Handbook of Industrial Drying. 4th ed. Boca Raton: CRC Press; 2015.

NAGAISH, T. Y. R. AÇAÍ (Euterpe oleracea Mart): extrativismo, características, energia e renda em uma comunidade na Ilha de Marajó/ PA. Dissertação de Mestrado, Universidade Federal Rural da Amazônia, 115p., 2007.

OLIVEIRA, S. B. L. Análise da matriz energética brasileira e o uso da biomassa no mercado nacional. Per. Cient. do Núcleo de Biociências da Universidade Metodista.Belo Horizonte, MG, v.07, n.04, ago. de 2014.

ORTIZ, L. Aprovechamiento energético de labiomasaforestal. Vigo Gamesal, 1996.330p.

SILVA, T. I.; ALMEIDA, A. C.; MONTEIRO, J. H. A.; SILVA, I. M. S.; ROCHA, B. R. P.; Uso do caroço de açaí como possibilidade de desenvolvimento sustentável do meio rural, da agricultura familiar e de eletrificação rural no Estado do Pará. An. 5. Enc. Energ. Meio Rural 2004. 